\title{
Treatment Response to Hydroxychloroquine, Lopinavir-Ritonavir, and Antibiotics for Moderate COVID-19: A First Report on the Pharmacological Outcomes from South Korea
}

Min Seo Kim, MD, Soon-Woo Jang, MD, KMD, Yu-Kyung Park, MD, Bong-Ok Kim, MD, PhD, Tae-Ho Hwang, DSS, PhD, Seok Ho Kang, MD , PhD, Won Jun Kim, MD, Park Sung Kyu, MD, Hea-Woon Park, MD, PhD, Wonjong Yang, MD, Joonyoung Jang, MD, Min Ho An, MD

The authors have withdrawn this manuscript because of the controversy about hydroxychloroquine and potential changes in results after peer-review, the authors intend to share their results in formal publication. Therefore, the authors do not wish this work to be cited as reference for the project. If you have any questions, please contact the corresponding author. 